\title{
The Implementation of Flipped Classroom Teaching Mode in Basic English Teaching for Tibetan College Students*
}

\author{
Jinfeng Liu \\ Gansu Normal University for Nationalities, Gansu Province, China
}

\begin{abstract}
For Tibetan college students to learn English, code-switching hinders them because Tibetan, Chinese, as well as English, form a trilingual environment for language learning. To improve such situation, this article studies the implementation of flipped classroom mode which can innovate the traditional teaching mode by fully highlighting the students' subjectivity as well as stimulating the students' initiative and enthusiasm.
\end{abstract}

Index Terms - flipped classroom mode, traditional teaching, Tibetan college students, Basic English

\section{INTRODUCTION}

As technology updates so rapidly, in parallel to the speed of development in technology, education should also trace it and push its development by innovating in learning method. However the teacher-centered traditional English teaching mode has been unable to meet students' individual development and career development needs. In face-to-face classroom, the teacher has been dominated students' learning outcomes and the curriculum is designed to prepare students for exam requirements. In this case, the Decade Development Plan of Education Informatization (2011-2020), which was issued by the Ministry of Education in China, has driven innovation in higher education. The Plan pointed out that for the development of education informatization, the use of digital technologies in classrooms should be based on high quality educational resources and the construction of an information and communication technology-based learning environment. The burst of information and educational technology inspired the implementation of the flipped classroom teaching mode. Meanwhile we should clarify the actual situation of education in China in case of superficial imitation, which helps us to realize the true student-based classroom teaching.

\section{DeFinition OF FLIPPED Class CONCEPT}

Flipped class is also called inverted class, which is defined from the perspective of learning process. Traditional knowledge transfer is mainly completed through the teacher's instruction while the knowledge internalization requires students to achieve it through doing their assignment or practicing after class. Flipped learning is a relatively modern instructional method which emphasizes effective use of class time by changing the traditional tasks of teachers and students inside and outside the classroom (Baepler, Walker, \& Driessen, 2014; Davies, Dean, \& Ball, 2013; O'Flaherty, \& Phillips, 2015). Flipped classroom teaching is a hybrid classroom teaching model, which is assisted by online homework, online testing as well as online community discussion to help students to discover learning problems, and then in the classroom teachers and students cooperate to solve problems, so that to achieve a deep grasp of the teaching content. In flipped class students are expected to acquire knowledge actively. Evidence also indicates that engaging students in active learning enhances their learning outcomes higher-order thinking, problem solving, and critical analysis and improves their motivation and attitudes (Freeman, 2007). Therefore the features of flipped class include: a) more interaction between the teacher and students; b) immediate feedback from the teacher; c) more devotion for students into learning; d) adjustable learning schedule for students according to their learning needs; e) more productive exercises under the supervision of the teacher in class (Goodwin, 2013).

\section{ThE DEVELOPMENT OF FLIPPED Class}

Lage, J.M., Platt, J.G. and Treglia, M. (2000), Flipped Classroom: A Path to Creating an Inclusive Learning Environment first proposed the concept of "flipped classroom". In 2007 chemistry teachers, Jonathan and Aaron recorded video so that students who couldn't attend class on time could study at home at Rocky Mountain Forest Park High School in the U.S. State of Colorado. On January 30, 2012, Woodland Park High School in the United States held the Flipped Classroom Open Day to promote the flipped classroom teaching model. Later, "Khan Academy" was

\footnotetext{
* This research was sponsored by the President Fund Project of Gansu Normal University for Nationalities of China. Grant Number [GSNUXM16-15].
} 
founded by Khan, which made flipped classroom become a new teaching model that many teachers are interested in. Arfstrom, K.M., Hamdan, N. and Mcknight, P. (2013) summarized flipped research on a global scale, they found that contribution to the success or fail of the flipped classes. Most studies on flipped classroom are on the effectiveness of activity design of flipped classroom, especially on peer learning and active learning strategies.

\section{RESEARCH ON FLipPed Class In SLL (SECOND LANGUAGe LEARNing)}

Jeong-eun Kim, Hyunjin, Mijung Jang and Hosung Nam researched the cognitive impacts of the flipped classroom model. Suranakkharin and Todsapon explored the effect of flipping a classroom on Thai learners' English collocation knowledge, and compared this instructional design with traditional instruction. Chi-Jen Lin; Gwo-Jen Hwang investigated factors affecting EFL Students' Oral Performance in a Flipped Classroom. Chuang, Hsueh-Hua; Weng, Chih-Yuan; Chen Ching-Huei explored individual characteristics, such as learners' motivation, learners' self-efficacy as well as learners' epistemology beliefs and so on, that might effect on learning result in a flipped classroom. Wang, Jun; An, Na; Wright, Clare learners outperform in oral proficiency with flipped learning method. Chen Hsieh, Jun Scott; Wu, Wen-Chi Vivian; Marek, Michael W. presented insights into the impact of theory-based flipped learning on motivation and idiomatic acquisition; student impressions of the online platform used, LINE; and offer recommendations for practice. (Ahmed 2016, Baranovic 2013, Engin 2014, Jehma 2016, Mireille 2014), who have proposed that significant improvements in writing performance can be largely attributed to flipped instruction. They also found that students had favorable attitudes towards this instructional model.

\section{Cognitive Style of Tibetan Students}

The cognitive style of Tibetan students generally belong to the field-dependent type. Due to the unique plateau environment, snow area culture as well as life custom influence, Tibetan students have formed the field dependence cognitive style since childhood. Witkin put forward field independence and field dependence of the two kinds of different cognitive styles: field independence is mainly rely on their own knowledge structure to analyze and solve problems independently, so their autonomous learning ability is stronger than field dependence, but their social sensitivity and social skills are considerable low, which result in they are not good at communication and cooperation with others; however field dependence are often affected by external factors, so they have weak independent learning ability and prefer group learning, hoping to get real-time information feedback. In addition, field dependence are good at learning and memorizing materials containing social content.

\section{Why SHOULD We FLIP THE CLASS}

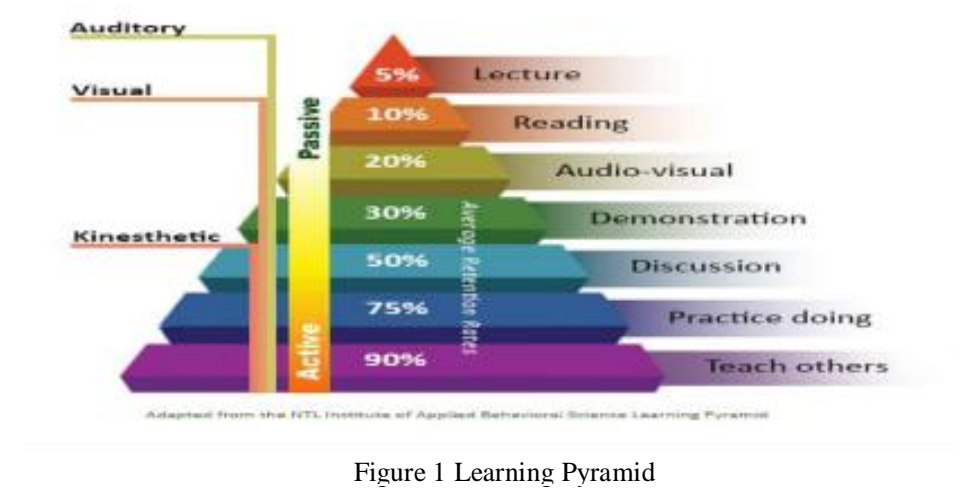

As figure 1 shows, the learning retention of active learning which includes discussion, practice doing, teach others is more higher than passive learning which includes lecture, reading, audiovisual, demonstration. Therefore with flipped learning, students' original role as passive listener is reversed to active participant in classroom activities (Baepler, Walker, \& Driessen, 2014; Davies, Dean, \& Ball, 2013; O'Flaherty, \& Phillips, 2015).

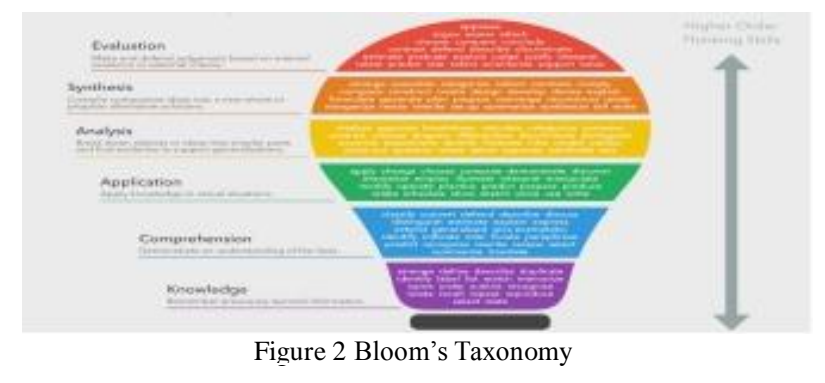


Figure 2 is Bloom's Taxonomy of educational objectives. Bloom's taxonomy (2019) is a set of three hierarchical models used to classify educational learning objectives into levels of complexity and specificity. The three lists cover the learning objectives in cognitive, affective and sensory domains. It plays an important role to measure higher and lower level cognitive skills. Apart from this, it also can evaluate how well students master the learning material based on the levels of the taxonomy. Flipped classrooms mode provides learners individual time and space to learn as well as produce their own ideas prior to class, which can free up lower level cognitive skills in the class, facilitate them to engage in more higher level cognitive capacity.

\section{How TO FLIP A CLASSROOM}

How to flip a classroom? It can be approached differently in practice. To begin, teachers adopting a flipped classroom approach can convert traditional face-to-face lectures into narrated PowerPoint videos, self-create instructional videos or select ready-made educational videos from websites or networks for learners to study prior to class as lecture replacements in order to free up class time for active learning activities (Moravec, Williams, Aguilar, \& O'Dowd, 2010). Sams and Bergmann pointed out that the value of teaching videos which applied in flipped class belonging to the lower levels of cognitive work, while the class time is reserved to deal with the cognitive work of higher levels, i.e. application, analysis, evaluation and creation (Sams, 2014). However applied flipped classroom model, it is not necessary to be a professional video producer, it is possible to use any source that explains the subject (Tucker, 2012). Simply put, flipped teaching can be conducted with various instructional videos, and other forms of assignments. The lectures are delivered to the students through electronic means outside of class time allowing students practice oral and dictation skills so that in class students carry out group cooperation. In this way knowledge transfer is not conducted by face-to-face instruction, but prepared by the teacher through creating some video lectures which related to teaching content, then the video will be sent to each student via the Internet, through watching the video before class, the process of imparting knowledge is implemented in extracurricular activities alone. In the classroom knowledge will be internalized through discussing and practicing activities. Nevertheless flipped learning is not only about how to use videos in lessons, but how to make use of class time with students. Flipped classroom is a kind of workshop in which students can discuss about lecture content, evaluate their skills, as well as interact with each other through hands-on activities. In this case the role of instructors is to guide and advise students during the class hour ( Educause, 2012). Flipped classroom is different from traditional teaching, it focuses on the students' ability of independent learning, students are responsible for their own learning, this kind of teaching mode fully respect the students subjectivity, it makes the students become the master of the classroom, extracurricular learning thoroughly change the traditional classroom, students learning will become a kind of personalized learning. Therefore we should dedicate to the construct and maintain the independent learning environment, which is a highly subjective and media-rich learning environment, so as to realize the students learning autonomy as well as liberate teachers from classroom teaching as much as possible, which is the original reform intention of the flipped classroom.

\section{The SituAtion OF BASIC ENGLish TeACHING}

\section{Background survey of Tibetan-Chinese bilingual students in Gansu Normal University for Nationalities}

Gansu Normal University for Nationalities, located in Gannan Tibetan autonomous prefecture, Gansu province P.R.China. There are diverse ethnic groups in the prefecture, which including Tibetan, Han, Hui and other ethnic groups, the total population is 680,000 , among which the Tibetan population is 340,000 , which accounting for about $50 \%$. Due to the influence of Lableng temple that located in Gannan Tibetan prefecture, therefore Gannan has become a holy land where the majority people of Anduo Tibetan areas yearn for, it also attracts students from Tianzhu county, Xizang Tibetan autonomous prefecture, Sichuan, Qinghai,Yunnan, and other Tibetan areas. According to a survey, the sources of Tibetan-Chinese bilingual students in Gansu Normal University for Nationalities are followed:

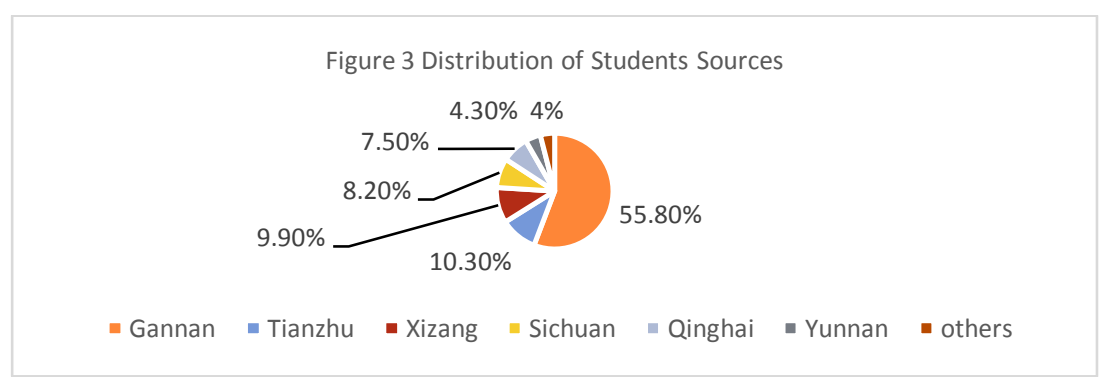




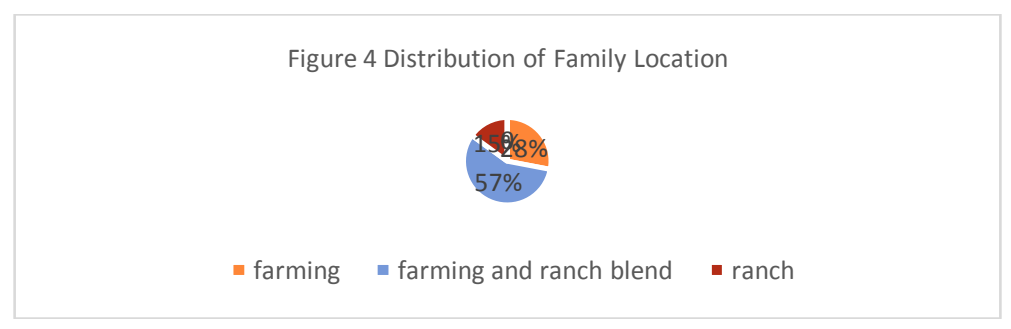

The impact of environments upon human behaviors has been long established ( Lewin 1936). As revealed, the students who come from ranch areas account for $15 \%$, those who come from farming and pastoral blend areas students are $57 \%$ as well as the farming area students take $28 \%$. From the point of language speaking, the majority of students who come from ranch areas speak Tibetan for the most part, they have little chance to communicate with other people in Chinese, however those who come from farming areas only speak Chinese, as for the students who come from farming and ranch blend areas, they can speak both Chinese and Tibetan. Totally more than half of the students are Tibetan speakers, which is a great challenge for English learning. Therefore educators and learners should be provided with good language learning environment. In this sense, integration of students' Information and Communication Technology ( ICT) skills into the learning process will probably yield better results in terms of language learning and production ( Ekmekci, 2017).

\section{Difficulties in Basic English teaching}

Being a compulsory course, Basic English is required to study by Gansu Normal University for Nationalities for Tibetan-Chinese bilingual students. In view of Tibetan college students whose starting point in English learning is very low, which results in encountering difficulties in vocabulary, phonetics, grammar and so on. It is inevitable to meet setbacks in English learning for Tibetan-Chinese bilingual students under the context of unique trilingual education, moreover Tibetan university students will meet difficulties which are brought by the cross-cultural communication. Among these barriers, code-switching is the greatest difficulty for Tibetan students in English learning because of the mother tongue hindering.

\section{NeCESSity of Implementing FlipPed ClassRoom in Basic English Teaching In Ethnic ColLeges}

\section{Disadvantages of traditional teaching in Basic English teaching}

According to the teaching syllabus, the teaching aim of Basic English is to cultivate and develop students' comprehensive application ability which includes listening, speaking, reading as well as writing, therefore we should endeavor to cultivate students' independent learning ability and cooperative learning ability based on the scaffolding theory. Therefore the teaching focus should be transformed to students. Which require teachers to innovate their instruction mode in order to lower difficulties as well as try to create more high efficient classes. However the fact is traditional classroom teaching mode is still the dominant stream, which in form of cramming explanation, allowing students to passively accept the instruction, in this case they will not internalize the lesson if they do not review timely after class. Apparently students' individual differences are ignored in this traditional class, the teacher regardless of individual learning ability. Therefore we should transfer this kind of teaching mode which ignores individual differences. In essence, the traditional teaching mode violates Confucius' education thought and runs counter to the concept of "student-centered" new curriculum reform education. The English basis of Tibetan-Chinese bilingual students are uneven, owing to some students come from Tibetan areas where the major nationality is Han, while others come from ranch areas. If we regardless the actual situation, with traditional teaching method alone the students who are from the Han dominated areas will find it too superficial, it is too hard to learn for the students who are from ranch areas. If students do not achieve the learning result successfully, due to the limitations of the classroom teaching, they will lose interest in English learning. According to Hung's (2015) research, ELLs have more positive attitudes toward learning in flipped classrooms.

\section{Necessity of flipped classroom in Basic English teaching}

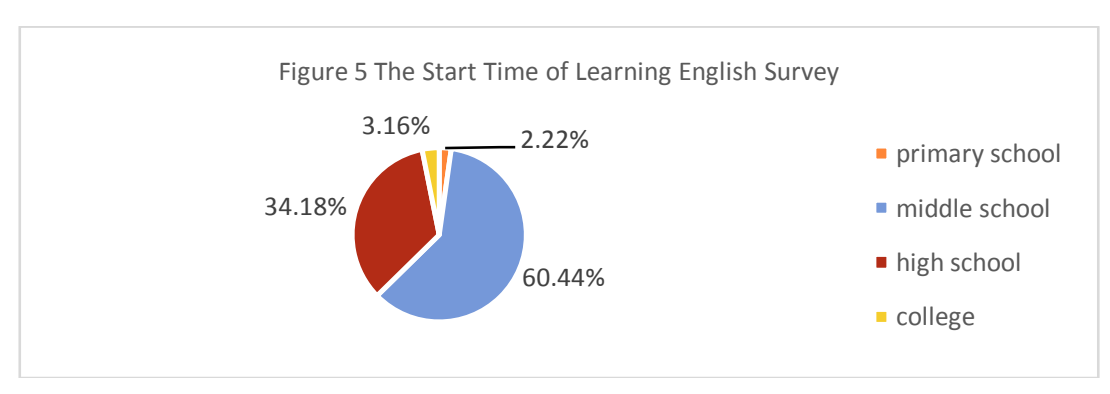

As it is showed, the majority of Tibetan college students started to learn English when they were in junior high school, which accounting for $60.44 \%, 34.18 \%$ students started learning English from senior high school, 2.22\% students 
started from primary school, and 3.16\% students started from college, there are quite a few students with lower starting point began to learn English in the high school. English is excluded in the college entrance exam, therefore English is ignored in ethnic region. After entering the university, they will suffer great difficulties. On the ground that the background survey of Tibetan-Chinese bilingual students, their English level is uneven, if we still employ the traditional teaching method, most of students will fall in difficulties, which bring about peer pressure. The impact of peer pressure is lessened for the ELL in flipped classroom because they arrive with the background knowledge and vocabulary needed for the topic and can interact with peers to gain a better grasp of the material (Lockwood, 2014). Recent years it has also witnessed an increasing number of young users communicating with each other through mobile messaging applications in Asia, such as LINE, Whats App, and WeChat. Studies have shown that instant and text messaging technologies can play important role in education because they provide not only platforms for socializing, sharing information, and communicating (Sweeny, 2010). In flipped classroom, teachers prepare micro videos and send to students through the network before the class. Videos incorporate both oral and visual stimuli, which increases the likelihood of teaching to the student's preferred modality (Kovarik, 2017). By means of lecture videos the teachers make use of the time for interacting between teachers and students rather than for instructing. Accordingly the teacher can spare more time to fulfill the learning and emotional demands of students (Goodwin\&Miller, 2013). Additionally, because the student may fast-forward or repeat sections of the video as needed, the pace of the lesson is individualized. The integration of information technologies and English courses will inevitably trigger a revolution in teaching ( Hu, 2015). One of the benefits often cited for flipping teaching is that students in the flipped classroom are given more opportunities to develop higher order thinking under teacher guidance and with peer support as needed, because in-class lectures that often require only lower levels of thinking skills in Bloom's (1984) taxonomy are replaced with instructional videos, without the cost of sacrificing learning content (Berrett, 2012).

\section{Problems and Countermeasures of IndePendent LeARning under the Background of FlipPed Class}

\section{Teachers' Negative Attitude towards flipped class}

Successful role changing is crucial for teachers in the new era, otherwise the students will never learn independently, never set their own learning goals independently, never learn to self-manage and make plan. The capacity of students is enhanced strictly accessing to knowledge, which impaired the teacher's authority, teachers will become a partner of the students, and they can conduct exploratory learning together. Therefore learning should not only limit to the classroom, it should also extend to the network. From individual learning to cooperative learning building a cooperative mechanism through the Internet. Teachers can cooperate with students by online. Evaluation methods can be done by big data accuracy. It enables teachers to keep students learning trends in time, to make timely summary and reflection, therefore to make reasonable and effective teaching decisions.

\section{Students weak awareness for independent learning}

Independent learning aims to promote the development of learners autonomy and independence. Students can acquire life-long learning skills by independent learning. Network learning is a new learning method that is different from traditional learning, which means that learners use network resources to assist learning. Therefore, first of all, students should be provided with psychological counseling, so that they can break the traditional stereotypes and accept this new learning style in a positive attitude. Web-based technological resources provide language learners with the privilege to choose learning materials according to their own learning interests and capabilities. Therefore, as helpful instructors, we should offer some useful learning ways which enable greater learners master.

\section{Less utilization of learning resources}

Due to the emergence of a large number of network resources, however students have a vague understanding for abundant network resources, let alone make full use of them. Although some students employ some learning resources what they are interested in, they cannot stick to the end, which is belong to ineffective learning. Facing a variety of learning resources, students unable to apply anything due to time constraints, so they can only achieve it through fragmented ubiquitous learning. Learning resources across industries, time as well as space, which are integrated into various forms of resources which meet the needs of learners to use fragmented time to learn in a ubiquitous learning environment as well as share high-quality learning resources.

\section{CONCLUSION}

Basic English course, as a compulsory course in ethnic colleges, is of great importance for talent cultivation in ethnic areas. Therefore, it is necessary to innovate teaching mode to improve the teaching quality. With the technology assisted, flipped instruction is an appropriate instructional design for teaching English as a Foreign Language, which is an innovation against traditional classroom teaching mode. With the favorable flipped classroom teaching mode, students are required to master cognitive contents by watching micro-video before class, which is facilitated to learn the materials at their own pace and the way that the materials were organized. They can watch videos and self-study vocabulary prior to class, so they can practice what they have learned with their classmates and actually use English for communicative purposes at class. The network is mainly provided for independent learning and independent inquiry, 
meanwhile the classroom is linked by cooperative learning, so as to realize the comprehensive development of all students' independent, creative, cooperative and other comprehensive qualities.

\section{REFERENCES}

[1] Ahmed, M.A.E.A.S. (2016). The effect of a flipping classroom on writing skill in English as a foreign language and students' attitude towards flipping. US-China Foreign Language. 14(2), 98-114.

[2] Sams, A. \& Bergmann, J. (2014). Flipped learning: Gateway to student engagement. Washington DC: International Society for Technology in Education.

[3] Baepler, P., Walker, J.D. \& Driessen, M. (2014). It's not about seat time: Blending, flipping and efficiency in active learning classrooms. Computers \& Education, 78, 227-236.

[4] Baranovic, K. (2013). Flipping the first-year composition classroom: Slouching toward the pedagogically hip. Unpublished Master's thesis, Southeast Missouri State University, United States.

[5] Berrett, D. (2012). How flipping the classroom can improve the traditional lecture. The Chronicle of Higher Education, 58(25), 16-18.

[6] Bloom's taxonomy. (2019). Retrieved from https:// en. wikipedia. org/ wiki/ Bloom\% 27s_taxonomy. Retrieved Mar. $25,2019$.

[7] Bloom, B. S. (1984). Taxonomy of educational objectives. Boston, MA: Allyn and Bacon.

[8] Davies, R. S., Dean, D.L. \& Ball, N. (2013). Flipping the classroom and instructional technology integration in a college-level information systems spreadsheet course. Education Tech Research, 61, 563-580.

[9] Ekmekci, E. (2017). The flipped writing classroom in Turkish EFL context: A comparative study on a new model. Distance Education, 18(2), 151-167.

[10] Engin, M. (2014). Extending the flipped classroom model: Developing second language writing skills through student-created digital videos. Journal of the Scholarship of Teaching and Learning. 14(5), 12-26.

[11] Freeman, S., O'Connor, E., Parks, J.W., Cunningham, M., Hurley, D., Haak, D., Dirks, C., \& Wenderoth, M.P. (2007). Prescribed active learning increases performance in introductory biology. CBE Life Sci Educ, 6:132-139.

[12] Goodwin, B. \& Miller, K. (2013). Evidence on flipped classrooms is still coming in. Educational Leadership, 23(3), 9-19.

[13] Goodwin, B. \& Miller, K. (2013). Evidence on flipped classrooms is still coming in. Educational Leadership, 70(6), 78-80.

[14] Hung, H. (2015). Flipping the classroom for English language learners to foster active learning. Computer Assisted Language Learning, 28(1), $81-96$.

[15] Hu, S. \& Jin, Y. (2015). Theories and practices in the integration of education technologies and English courses. China Educational Technology, 48(4), 24-31.

[16] Jehma, H. (2016). Flipped learning as a strategy for an effective EFL classroom. Asian EFL Journal Professional Teaching Articles. 90, 54-65.

[17] Lewin, K. (1936). Principles of topological psychology. New York: McGraw-Hill

[18] Lockwood, R. B. (2014). Flip it! Strategies for the ESL classroom. Ann Arbor: University of Michigan Press.

[19] Madeline, K. (2017). Flip on the lamp: tips for lighting the way for ELLs in the flipped classroom. KDP New Teacher Advocate.

[20] Mireille, F. (2014). The impact of using flipped classroom instruction on the writing performance of twelfth grade female Emirati students in the Applied Technology High School (ATHS). Unpublished Master's thesis, the British University, Dubai, Emirates.

[21] Moravec, M., Williams, A., Aguilar-Roca, N., \& O’Dowd, D. K. (2010). Learn before lecture: A strategy that improves learning outcomes in a large introductory biology class. CBE Life Sciences Education, 9(4), 473-481.

[22] O'Flaherty, J. \& Phillips, C. (2015). The use of flipped classrooms in higher education: A scoping review. The Internet and Higher Education, 25, 85-95.

[23] Sweeny, S.M. (2010). Writing for the instant messaging and text messaging generation: Using new literacy to support writing instruction. Adolescent \& Adult Literacy, 54, 121-130.

[24] Tucker, B. (2012). The flipped classroom. Education Next, 12(1), 82-83.

Jinfeng Liu was born in Lanzhou, China in 1980. She received her M.A degree in Higher Pedagogy from Lanzhou University, China in 2015.

She is currently a lecturer in Gansu Normal University for Nationalities, China. Her research interest is English Teaching Methodology.

Ms. Liu got Excellent Head Teacher Award in 2012 as well as Excellent Instructor Award of National English Competition for College Students in 2014. 